\title{
Impact of Pediatric Acute Otitis Media on Child and Parental Quality of Life and Associated Productivity Loss in Malaysia: A Prospective Observational Study
}

\author{
Bruce Crawford $^{1} \cdot$ Siti Sabzah Mohd Hashim ${ }^{2} \cdot$ Narayanan Prepageran $^{3}$. \\ Goh Bee See ${ }^{4} \cdot$ Genevieve Meier $^{5} \cdot$ Keiko Wada $^{1} \cdot$ Cheryl Coon $^{6,7}$. \\ Emmanuelle Delgleize $^{5} \cdot$ Michael DeRosa $^{6}$
}

Published online: 25 November 2016

(c) The Author(s) 2016. This article is published with open access at Springerlink.com

\begin{abstract}
Background Acute otitis media (AOM) affects both child and parental quality of life (QoL). Data on QoL associated with AOM in Malaysia is sparse, and the burden of indirect costs have not been previously reported.

Objective To determine the effect of pediatric AOM on child and parental QoL in Malaysia and its economic impact (indirect costs).

Methods We utilized a set of QoL questionnaires (PARAOM-QOL, OM-6, and EQ-5D) combined with questions addressing work/productivity loss and financial costs associated with caring for a child during his or her illness in an observational, multicenter, prospective study.
\end{abstract}

Electronic supplementary material The online version of this article (doi:10.1007/s40801-016-0099-9) contains supplementary material, which is available to authorized users.

\author{
Bruce Crawford \\ bcrawford@jp.imshealth.com \\ Siti Sabzah Mohd Hashim \\ dr_ctsabzah@yahoo.com \\ Narayanan Prepageran \\ prepageran@yahoo.com \\ Goh Bee See \\ irenegbs@yahoo.com \\ Genevieve Meier \\ gengagee@yahoo.com \\ Keiko Wada \\ kkwada@jp.imshealth.com \\ Cheryl Coon \\ ccoon@outcometrix.com \\ Emmanuelle Delgleize \\ emmanuelle.delgleize@gsk.com
}

Results One hundred and ten AOM patients aged $\leq 5$ years were included in the analysis. The majority of respondents were the patient's mother. Parental QoL was negatively affected for both emotional and daily disturbance scales, but the level of disturbance was low. Using OM-6, the greatest negative impact was on the child's QoL, followed by caregiver concerns, physical suffering, and emotional distress. Using EQ-5D, a moderately positive relationship between parents' emotional disturbance and daily disturbance, and a weak, negative correlation between parental emotional disturbance and parental health status was found. Parents with paid employment took an average of $21 \mathrm{~h}$ from work to care for their child, at an average cost of 321.8 Malaysian ringgit (US\$97) in addition to their contribution to direct medical costs. Productivity losses whilst at work, uncompensated wage losses, and leisure time losses are also reported.

Michael DeRosa

michael.derosa@adelphivalues.com

1 IMS Health, Toranomon Towers Office, 4-1-28 Toranomon, Minato-ku, Tokyo, Japan

2 Otolaryngology Service, Ministry of Health, Jalan Langgar, 05460 Alor Setar, Kedah, Malaysia

3 Department of Otolaryngology, Faculty of Medicine, University Malaya, 50603 Kuala Lumpur, Malaysia

4 Department of Otorhinolaryngology Head and Neck Surgery, Universiti Kebangsaan Malaysia (UKM) Medical Centre, Jalan Yaacob Latif, Cheras, 56000 Kuala Lumpur, Malaysia

5 GSK Vaccines, Avenue Fleming 20, 1300 Wavre, Belgium

6 Adelphi Values, Congress Street 290, Boston 02210, USA

7 Present Address: Outcometrix, Tucson, AZ, USA 
Conclusions This study found that AOM is associated with some negative impact on parental QoL and significant economic impact at both patient and societal levels. The findings provide useful data on healthcare resource utilization and disease burden of AOM in Malaysia.

\section{Key Points}

We utilized a suite of tools to examine QoL, medical resource use, and indirect costs associated with childhood AOM in Malaysia.

Parents reported a negative impact of AOM on parental and child QoL.

Indirect healthcare costs related to parental working days lost and productivity loss represent an additional economic burden.

\section{Introduction}

Acute otitis media (AOM) presents a significant disease burden in children, especially those $\leq 5$ years of age, and is one of the most common reasons for young children to visit physicians and receive antibiotic prescriptions [1, 2]. In developed countries, up to $80 \%$ of children have had at least one episode of AOM by 3 years of age [1,2]. Although up to $70 \%$ of affected children spontaneously achieve complete clinical resolution within 1-2 weeks, the recurrence rate is high; $5-15 \%$ of all children experience four or more episodes in 1 year, with $65 \%$ of children at 5 years having three or more episodes [2-6].

Globally, there are an estimated 709 million AOM cases each year, a global annual incidence rate of $10.8 \%$, with $51 \%$ of episodes occurring in children $<5$ years of age [2]. The incidence/prevalence of AOM varies across different geographical locations, and direct comparisons should be used with caution. An annual incidence of $3.6 \%$ is reported for central Europe [2], while in the Southeast Asia region, where the present study was conducted, the annual incidence is $8.2 \%$. The prevalence of OM (both acute and chronic) in school-age children ranges widely across the region, from $3.3 \%$ in Thailand to $12.2 \%$ in the Philippines [2], with a prevalence of chronic disease [otitis media with effusion (OME)] in Malaysian children aged $\leq 12$ years of $2.3 \%$ [7].

The effect of OM on quality of life (QoL) has also been reported, although these usually involve patients with recurrent AOM or patients with more chronic infection.
While such studies confirm a negative impact upon patient QoL, they also report that AOM negatively impacts the QoL of the child's family due to increased caregiver concerns and burden $[5,8-12]$. OM is also associated with a considerable economic burden [1]. In Malaysia, the overall direct healthcare costs for AOM (based upon 2010 costs) have been estimated to be 667 million Malaysian ringgit (RM)—equivalent to US\$207 million [13]. However, indirect costs also contribute to the overall economic burden of AOM, and studies suggest that the impact upon caregivers is also associated with productivity losses, which carry additional costs [14].

Data on the clinical and QoL impact of AOM and on the indirect cost contribution to the economic burden is relatively lacking in Asia, compared with other regions, and particularly so for Malaysia. While the prevalence of chronic OME in Malaysia and treatment guidance have been reported [7, 15-17], similar data for AOM is lacking. To date, no assessment of the impact of AOM on QoL in patients or caregivers has been reported. Furthermore, while the estimated direct healthcare costs for AOM in Malaysia have been reported [13], such data were calculated across the whole population, rather than younger children who represent the majority of AOM cases [7, 15-17]. In addition, this model did not include data for any indirect costs associated with caregiver productivity loss [13].

The objective of this study was to assess the impact of AOM specifically in the population at greatest risk (younger children $\leq 5$ years of age), on both patient and caregiver QoL, and to assess treatment and resource use in this population. Additional aims were to collect factors contributing to indirect costs (i.e., work and productivity loss) to provide data to inform more robust evaluations of the economic burden of AOM in Malaysia.

\section{Methods}

\subsection{Study Setting and Study Population}

This was a prospective, multicenter, observational study. Children and their caregivers were recruited from three separate sites in Malaysia: the University of Malaya and the National University of Malaysia hospitals, and Sultanah Bahiyah Hospital, a large regional center which functions as a referral center for over 30 hospitals and clinics in the northwestern state of Kedah. Following ethical approval at each site, participating physicians recruited patients from their own practice [outpatient unit within ear, nose, and throat (ENT) departments] and were also allowed to ask other departments within their hospital (i.e., pediatrics, emergency room, and/or general outpatient clinic) to refer 
potential patients to be considered for study inclusion. Patients were included in the study from March 2013 to April 2014. Inclusion criteria were: (1) physician diagnosis of AOM, confirmed using otoscopy and/or tympanometry, in accordance with local guidelines; (2) patient $\leq 5$ years of age; (3) patient's parent/caregiver able to speak, read, and write local languages (i.e., Malay or English); (4) willing and able to participate in a 35-min interview; (5) provided informed consent.

Subjects and their parents/caregivers participated in two separate visits. At visit 1, eligible subjects were identified by recruiting clinicians, and clinical baseline data collected. AOM was categorized as either being recurrent, in which subjects had to have at least one ear infection within the last 3 months prior to the most recent AOM episode, or non-recurrent in those not meeting this criterion. At visit 2, within the next 14-30 days, a 35-min face-to-face interview was conducted, either at the clinic or a location agreed upon by the interview respondent, to collect data on QoL, resource utilization, work absences, and AOM symptoms.

\subsection{Study Assessment Overview}

Data for descriptive analyses included demographic and baseline variables of the children and their parents: age, gender, parent's education, household income, respondent's relationship to the patient, medical insurance, and day-care arrangements (made during the recent AOM episode). AOM disease characteristics collected included duration of the current AOM episode, past history of any AOM, and presence of symptoms at Visit 2. AOM treatment characteristics included specialty of the attending physician, type of treatment procedure, type of medication prescribed (if any), and whether hospitalization was required.

All interviews were conducted in the local language (Bahasa Malay). As described below, a suite of tools were used to examine QoL, medical resource use, and indirect costs associated with the AOM episode. All QoL instruments were linguistically validated for the Malaysian population in accordance with previously reported principles so as to achieve concordance between original and translated versions, while maintaining content validity across different cultures [18, 19]. In this we adopted established principles: dual forward translation from the original language source document, reconciliation of the dual forward translation, back translation, and reconciliation of the back and forward translations. Differences were resolved by using the most appropriate or frequently used terms as appropriate. The final version was then evaluated by the study interviewers prior to their use.

\subsection{Quality-of-Life (QoL) Assessments}

The Parental QoL questionnaire for recurrent ENT infection in their children (PAR-ENT-QOL) [10] was adapted to create an AOM-specific 15-item questionnaire, the Parental Acute Otitis Media Quality of Life questionnaire (PARAOM-QOL) as previously reported [20]. This measures the impact of AOM on two parental QoL scales, parent's emotional disturbance (ES) and daily disturbance (DDS), with each scale scored from 0 (best) to 100 (worst). The burden of AOM on affected children in AOM-specific domains was measured with the Otitis Media-6 questionnaire (OM-6) [9, 21]. OM-6 is a brief and easy-to-use, disease-specific instrument, consisting of six functional health status, mainly symptom-oriented domains (physical suffering, hearing loss, speech impairment, emotional distress, activity limitations, and caregiver concerns) [9]. While originally scored on a 7-point Likert scale, this has been modified so that item and summary scores were adjusted to $0-100$ scales with 0 as "no impact" and 100 as "worst possible impact," as previously reported [21]. We also added an additional question (Item 7) regarding the overall impression of the child's QoL, as used in a previous study [12]. The EuroQol five-dimension questionnaire (EQ-5D), which assesses five QoL domains, was used to measure parents' current health state [22]. EQ-5D has been shown to have good validity in assessing QoL in Malaysia, and the recently reported EQ-5D social tariff applicable to the Malaysian population was also applied [23, 24]. It should be recognized that EQ-5D is more commonly used for assessing the impact of long-term chronic conditions on patient QoL.

For the present study, a parent/caregiver questionnaire was also developed (Electronic Supplementary Material 1), modified from a 24-item internet questionnaire used to examine resource use and direct/indirect costs associated with AOM in young children in Europe [14]. Our experience with the Malaysian population resulted in our choice of a questionnaire delivered in a face-to-face interview format rather than via the internet. The 22 -item parent questionnaire we used captures data from parents regarding their child's most recent AOM episode, focusing on the 15 days following the diagnosis of the child's AOM, and also data on parent/family background, disease course, medical resource use, medication use, and productivity loss (work days lost, productivity loss, and leisure time loss).

\subsection{Productivity and Indirect Cost Assessments}

Indirect costs based upon parents' productivity loss due to their child's AOM were calculated based on the following parent questionnaire items: wages lost due to the most recent AOM episode; number of work hours lost by 
parents, and productivity lost (estimated by the amount of extra hours that would have been needed for them to be as productive as usual). Lost leisure time was also collected. Costs were presented in RM, with selected costs in US dollars based upon December 2014 exchange rates (US\$1 = $3.33 \mathrm{RM}$ ).

\subsection{Statistical Analyses}

Descriptive analyses for all assessments were conducted with SAS 9.4 (SAS Institute Inc., Cary, NC, USA). For clinical assessments, continuous variables were described by presenting the mean, standard deviation (SD), median, minimum, and maximum. Categorical variables were described by presenting the number and percentage of subjects.

Disutility was considered using two methods: (1) Malaysian normative data, as reported by Shafie et al. [23], were used as pre-diagnosis values with disutility calculated as the gender-referenced norms minus the observed EQ-5D s score for each person; and (2) best imaginable health was used as the pre-diagnosis value, with disutility calculated as 1-one minus the observed EQ-5D score for each person. We used Pearson's correlation coefficient to analyze correlations among all QoL variables. Study development/reporting was in accordance with the Strengthening the Reporting of Observational Studies in Epidemiology (STROBE) guidelines [25] (Electronic Supplementary Material 2).

\section{Results}

\subsection{Patient and Parent Characteristics}

A total of 144 patients were recruited to the study; 34 patients whose parent could not be interviewed within 30 days of the clinic visit (Visit 2) were excluded as perprotocol analysis, with 110 AOM patients and related-case interviews included in the final analysis (Fig. 1). More than half the patients $(n=63,57.3 \%)$ were male, with a mean age of 2.1 years (SD, 1.6). All interview respondents were the child's parent, most ( $n=96,87.3 \%$ ) being the patient's mother (Table 1). Prior to the present AOM episode, almost half of the children normally stayed at home with their parent $(n=50,45.5 \%), 37 \%$ attended either a school or nursery), with the rest supervised by others (relatives or babysitters).

For the majority of children, the recent AOM episode was the first reported ear infection $(n=86,78.2 \%)$. While 24 children $(21.8 \%)$ had experienced at least one previous episode of ear infection, only four $(3.6 \%)$ had ear infection within the past 3 months, and so were considered to have "recurrent AOM," with 106 children (96.4\%) classified as non-recurrent AOM in accordance with the study protocol.

Interviews were conducted between 14 and 30 days after the clinic visit, with a mean of $17.7 \pm 4.2$ days, and a median of 16.5 days after the clinic visit. Over two-thirds of the patients did not have any AOM symptoms at the time of the interview $(n=74,67.3 \%)$.

\subsection{Healthcare Utilization Burden}

Most of the patients $(n=94,85.5 \%)$ received a diagnosis of AOM by the study recruiting clinicians, all of whom were ENT specialists. As some patients were referred from other departments within the same hospital, nine patients $(8.2 \%)$ were initially diagnosed by a pediatrician and seven patients $(6.4 \%)$ by a general practitioner (GP). Most patients $(n=97,88.2 \%)$ only consulted the diagnosing clinician for treatment, while $11.8 \%$ of patients $(n=13)$ attended other practitioners (either a pediatrician or an audiologist) for additional care. The majority of patients received antibiotics $(87.3 \%)$, and many parents also bought various over-the-counter medications; eight patients $(7.3 \%)$ were hospitalized due to the most recent AOM episode (Table 2).

\subsection{Quality of Life}

PAR-AOM-QOL was used to measure the impact of AOM on the two QoL scales, parent's ES and DDS. Parental QoL was negatively affected by AOM for both scales, but the level of disturbance was low, with a mean ES of 24.66 (SD, 17.14), a mean DDS of 15.45 (SD, 16.93), and a mean total score of 19.95 (SD, 14.27) (Fig. 2). The burden of AOM on affected children was measured with OM-6. The greatest negative impact was reported on the child's QoL with a mean of 66.55 (SD, 20.25), and a median of 70.00. Caregiver concerns, physical suffering, and emotional distress were also negatively affected. The mean summary score for OM-6 was 24.70 (SD, 14.03) (Fig. 3). EQ-5D was used to measure parents' current health state. For the overall cohort, parents reported their own health state to be relatively good, with a mean index value of 0.92 (Table 3). EQ-5D disutility scores indicated parental perception of their own health status was relatively good after resolution of their child's illness. While it was planned to perform analyses of differences between recurrent AOM versus non-recurrent AOM, due to the small numbers of patients with recurrent $\mathrm{AOM}$, it was not possible to perform meaningful comparisons.

We performed correlations between the PAR-AOMQOL scores, OM-6 QoL scores, and parental EQ-5D index values (Table 4). There was a positive relationship between parents' emotional disturbance and daily disturbance 
Fig. 1 Study flowchart showing patient disposition. Data were evaluated for the 110 subjects whose parents were interviewed at visit 2 (within 14-30 days of initial clinical assessment)

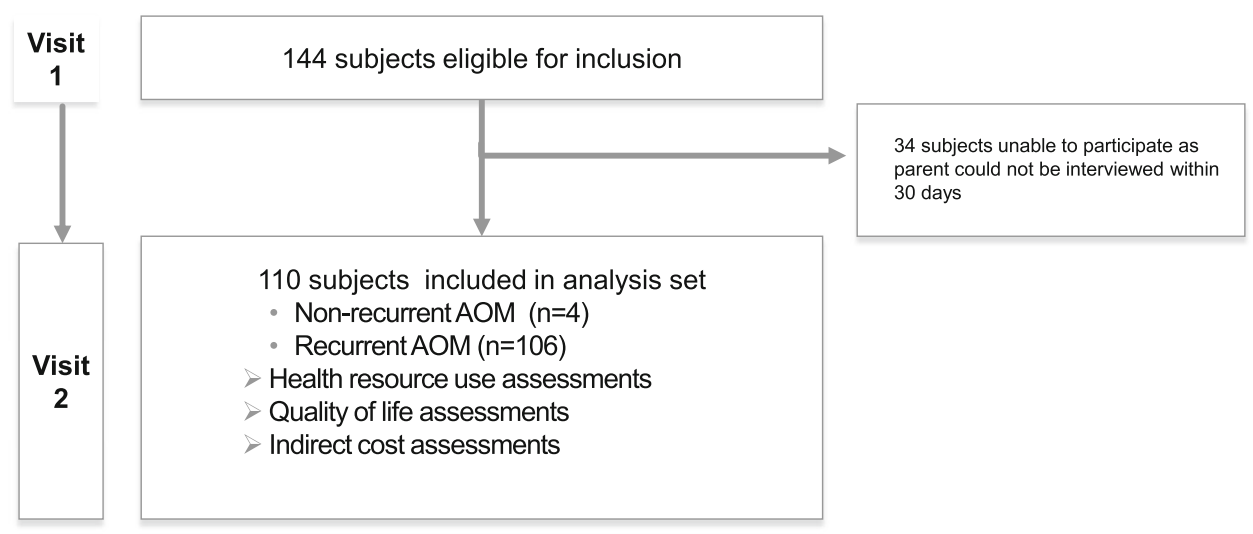

(coefficient $=0.53)$ and between parents' emotional disturbance and their child's QoL based on OM-6 items (coefficient $=0.37$ ). Most other burden of illness variables were weakly correlated (Table 4).

\subsection{Indirect Costs (Work Loss and Productivity Loss)}

We examined time away from usual day-care, patterns of parental/caregiver working days lost, and productivity loss as a result of their child's AOM (and the associated financial loss). Some estimation of direct healthcare costs was also made.

For those 60 children where usual day-care was provided by someone other than their parents, data were available for 27 children. For these, the average time lost, i.e., absence from their normal day-care activity (school, nursery, or any other form of their usual day-care) was 31.1 h. In these cases, day-care during the AOM episode was provided either by parents or grandparents. Children with recurrent AOM were away from usual care for almost three times longer, $72.0 \mathrm{~h}$, compared to those with a first or nonrecurrent episode of AOM.

Average parental working hours lost and productivity loss are outlined in Table 5 and financial loss in Table 6. Forty-two parents (38.2\%) reported taking time off from work, with an average of 20.9 work hours lost due to their child's AOM. Only four parents were compensated for absence with sickness allowance and/or paid sick time, with an average of $18.0 \mathrm{~h}$ lost and compensated for. Uncompensated losses also arose, with 46 parents $(41.8 \%$ of all parents; 36 mothers and 10 fathers) reporting uncompensated work loss (for mothers, an average of 19.7 $\mathrm{h}$, for fathers, $23.4 \mathrm{~h}$ ). Reduced productivity for those attending work was reported by 44 parents $(40 \%)$ with an average of $3.6 \mathrm{~h}$ lost.

When calculating financial loss due to lost hours, an average parental wage loss of $321.8 \mathrm{RM}$ (range 16.4-1875.2 RM; US\$96.6 [range US\$4.92-568.2]) arose due to their child's AOM (Table 6). Additionally, for lost wages compensated by funded sickness allowance and/or paid sick time, compensation ranged from 112.5 to 468.8 RM (US\$33.8-140.8). Uncompensated wage losses were 319.9 RM [US\$96.1] for the mothers and $379.8 \mathrm{RM}$ [US\$114.1] for the fathers. The estimated financial cost of reduced productivity was a mean of 53.3 RM (US\$16.0). It should be recognized that across this study population substantial ranges for time-loss and financial costs were reported.

\section{Discussion}

While data for the impact of AOM upon patients, caregivers, and clinical services in developed countries is widely reported, at present there is far more limited data reported for developing countries, and few data for Malaysia. The current study aimed to understand the burden of AOM in young children in Malaysia, assess healthcare resource use, evaluate its impact upon QoL (from both the child's and the parent's perspective), and determine indirect costs to patients associated with work and productivity loss. We recruited a total of 110 children with AOM, and their parents (mostly the mothers) answered a set of QoL questionnaires and the parent questionnaire through face-to-face interviews.

In our cohort, all patients had a physician diagnosis of $\mathrm{AOM}$, and for most, a basic AOM-related examination, such as ear inspection and cleaning (including suction), was performed. A small proportion of children were hospitalized, and while most children received antibiotics, the relatively high rate of antibiotic use is similar to that reported in previous studies [3, 14, 26, 27]. More intensive treatment (e.g., ventilation tube placement, hospitalization) was required as a consequence of AOM complications in a small number of both recurrent and non-recurrent AOM cases. Our analyses were not planned to measure differences based upon treatment intensity, and it is likely that 
Table 1 Patient and parent demographics $(n=110)$

\begin{tabular}{|c|c|}
\hline \multicolumn{2}{|l|}{ Demographic $(n=110)$} \\
\hline \multicolumn{2}{|l|}{ Child's age (years) } \\
\hline Mean (SD) & $2.1(1.6)$ \\
\hline Median & 1.45 \\
\hline Min-max & $0.1-5.5$ \\
\hline \multicolumn{2}{|l|}{ Child's gender, $n(\%)$} \\
\hline Female & $47(42.7 \%$ \\
\hline Male & $63(57.3 \%$ \\
\hline \multicolumn{2}{|l|}{ Day-care type, $n(\%)$} \\
\hline Home with parent & $50(45.5 \%$ \\
\hline Nursery & $32(29.1 \%$ \\
\hline School & $9(8.2 \%)$ \\
\hline Family, e.g. grandparent & $3(2.7 \%)$ \\
\hline Other, e.g. babysitter & $16(14.6 \%$ \\
\hline \multicolumn{2}{|l|}{ Respondent, $n(\%)$} \\
\hline Mother & $96(87.3 \%)$ \\
\hline Father & $14(12.7 \%)$ \\
\hline \multicolumn{2}{|c|}{ Respondent's education level, $n(\%)$} \\
\hline Primary school & $4(3.6 \%)$ \\
\hline Secondary school & $44(40.0 \%)$ \\
\hline Associate degree & $27(24.6 \%)$ \\
\hline Bachelor degree & $30(27.3 \%)$ \\
\hline Graduate degree & $4(3.6 \%)$ \\
\hline Other & $1(0.9 \%)$ \\
\hline \multicolumn{2}{|c|}{ Monthly household income (RM), $n(\%)$} \\
\hline$\leq 400$ & $2(1.8 \%)$ \\
\hline $401-1500$ & $25(22.7 \%)$ \\
\hline $1501-3000$ & $24(21.8 \%)$ \\
\hline $3001-4500$ & $18(16.4 \%)$ \\
\hline $4501-6000$ & $19(17.3 \%$ \\
\hline $6001-7500$ & $15(13.6 \%)$ \\
\hline$\geq 7501$ & $7(6.4 \%)$ \\
\hline \multicolumn{2}{|c|}{ Type of health insurance used, $n(\%)$} \\
\hline No insurance & $55(50.0 \%)$ \\
\hline Private insurance & $37(33.6 \%)$ \\
\hline Public insurance & $17(15.5 \%$ \\
\hline Other & $4(3.6 \%)$ \\
\hline
\end{tabular}

$R M$ Malaysian ringgit

this more intensive care (albeit in $<10 \%$ of cases) had an impact upon both parental and child QoL, for reasons of health concern and possibly any personal economic consequences.

We found that, in Malaysia, AOM has a negative impact on affected children (as measured by OM-6) and their parents (PAR-AOM-QOL) in terms of their QoL and caregiver concerns. This is consistent with outcomes reported in previous studies in European populations
Table 2 Treatment and healthcare resource use for the current acute otitis media (AOM) episode $(n=110)$

\begin{tabular}{|c|c|}
\hline Resource use & $\mathrm{n}(\%)$ \\
\hline \multicolumn{2}{|c|}{ Type of doctor visited for AOM diagnosis } \\
\hline ENT specialist & $94(85.5 \%)$ \\
\hline Pediatrician & $9(8.2 \%)$ \\
\hline General practitioner & $7(6.4 \%)$ \\
\hline \multicolumn{2}{|c|}{ Use of other healthcare professionals } \\
\hline No & $97(88.2 \%)$ \\
\hline Yes & $13(11.8 \%)$ \\
\hline Pediatrician & $8(7.3 \%)$ \\
\hline Audiologist & $5(4.6 \%)$ \\
\hline \multicolumn{2}{|c|}{ Hospitalization due to the current $\mathrm{AOM}$} \\
\hline No & $102(92.7 \%)$ \\
\hline Yes & $8(7.3 \%)$ \\
\hline \multicolumn{2}{|c|}{ Medications for the current $\mathrm{AOM}^{\mathrm{a}}$} \\
\hline Antibiotic & $96(87.3 \%)$ \\
\hline Pain killer & $22(20.0 \%)$ \\
\hline Antipyretic & $3(2.7 \%)$ \\
\hline \multicolumn{2}{|c|}{ Procedure during the clinic visit ${ }^{\mathrm{b}}$} \\
\hline Ventilation tube insertion & $10(9.1 \%)$ \\
\hline Audiometry & $6(5.5 \%)$ \\
\hline Tympanocentesis & $4(3.6 \%)$ \\
\hline Aural swab & $2(1.8 \%)$ \\
\hline Camera inspection & $2(1.8 \%)$ \\
\hline Radiology & $1(0.9 \%)$ \\
\hline Aural dressing & $1(0.9 \%)$ \\
\hline
\end{tabular}

ENT ear, nose and throat

${ }^{\text {a }}$ Multiple medications possible. Percentages may not add up to 100

b Multiple procedures may have been used. Percentages may not add up to 100

\section{PAR-AOM-QOL scores by group}

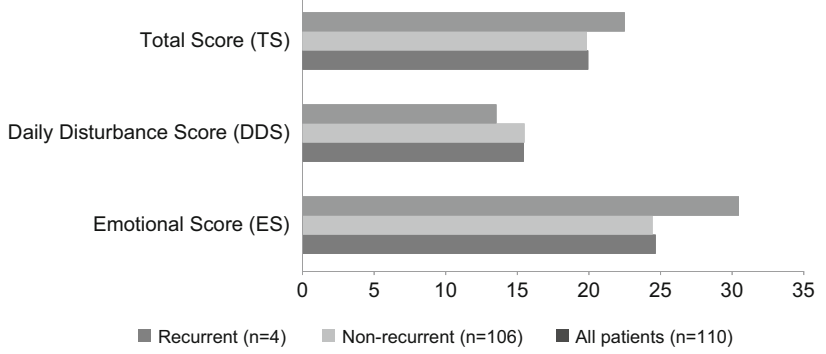

Fig. 2 Proportion of responses for the Parental Acute Otitis Media Quality of Life questionnaire (PAR-AOM-QOL) questionnaire. The PAR-AOM-QOL scores range from 0 to 100, with higher scores associated with worse quality of life

$[5,11,12,14]$. For example, the effect on a child's QoL is similar to that seen in patients with recurrent AOM reported in a previous study from The Netherlands [5], 
although the QoL scores in our study were generally lower (indicating less negative impact) than those of the Dutch study (which involved more severe cases). Previous studies have also reported that the negative impact of AOM on a

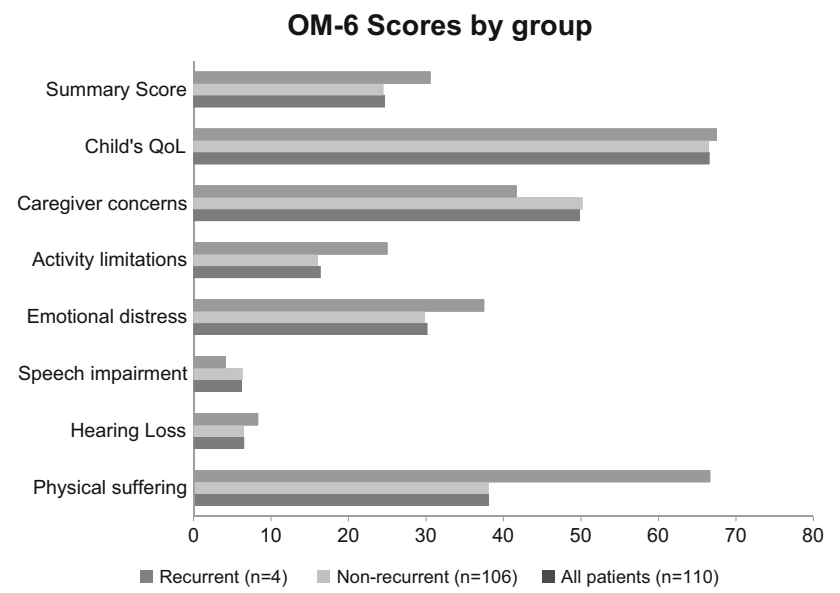

Fig. 3 Proportion of responses for the Otitis Media-6 (OM-6) questionnaire. The OM- 6 scores range from 0 to 100 with higher scores associated with greater negative effect of the ear infection on the child/caregiver child's QoL is greater with an increasing number of AOM episodes, and in children with more severe disease [11, 12]. In our study, we found a smaller impact on child AOM than that reported in these studies, consistent with the less severe disease and the small number of recurrent AOM cases seen in our cohort. The lower scores may also reflect, in part, that in some cases parents were interviewed after their child's recovery. From the PAR-AOM-QOL questionnaire we found low levels of disturbance for parental QoL, and parents reported their own health state to be relatively good across all EQ-5D indices. This suggests that the greatest impact upon parental QoL is concern for their child's health.

We also examined indirect, non-medical costs associated with lost working days and productivity loss while at work (Tables 4, 5). To place the financial loss in the context of average household income, in 2014 the national median monthly household income was 4585 RM (US\$1377), although regional differences and differences between urban and rural communities exist. In our study, substantial disparities were seen within the study participants, with approximately $65 \%$ of participants below this national average, although this in part may reflect

Table 3 Parental EQ-5D index values and disutility values by group

\begin{tabular}{llll}
\hline EQ-5D ratings & All patients $(n=110)$ & Recurrent $(n=4)$ & Non-recurrent $(n=106)$ \\
\hline EQ-5D Index ${ }^{\mathrm{a}}$ & & & $0.92(0.08)$ \\
Mean (SD) & $0.92(0.10)$ & $0.78(0.27)$ & 1.00 \\
Median & 0.94 & 0.87 & $0.73-1.00$ \\
Min-max & $0.38-1.00$ & $0.38-1.00$ & $0.01(0.08)$ \\
Disutility 1 (gender norm - EQ-5D) & & $0.15(0.27)$ & -0.06 \\
Mean (SD) & $0.01(0.10)$ & 0.06 & -0.07 to 0.20 \\
Median & 0.00 & -0.06 to 0.55 & \\
Min-max & -0.07 to 0.55 & &
\end{tabular}

$E Q-5 D$ EuroQoL-5 Dimension questionnaire

${ }^{a}$ The Malaysian EQ-5D Index-based health state is scored between 0.131 (worst imaginable health state) and 1 (best imaginable health state) [26]

b The EQ-5D Disutility Score is based on Shafie et al. [25]; gender norms minus observed EQ-5D score. Lower scores are better

Table 4 Correlations of burden-of-illness variables $(n=110)$

\begin{tabular}{|c|c|c|c|c|c|c|}
\hline Burden of illness variable & $\begin{array}{l}\text { Parent emotional } \\
\text { disturbance }\end{array}$ & $\begin{array}{l}\text { Parent daily } \\
\text { disturbance }\end{array}$ & $\begin{array}{l}\text { Child QoL based } \\
\text { on OM-6 }\end{array}$ & $\begin{array}{l}\text { Caregiver } \\
\text { concerns }\end{array}$ & $\begin{array}{l}\text { Parents' perception } \\
\text { of child QoL }\end{array}$ & $\begin{array}{l}\text { Parent } \\
\text { health state }\end{array}$ \\
\hline Parent emotional disturbance & 1.00 & & & & & \\
\hline Parent daily disturbance & 0.53 & 1.00 & - & - & - & - \\
\hline Child QoL based on OM-6 & 0.37 & 0.23 & 1.00 & - & - & - \\
\hline Caregiver concerns & 0.34 & 0.28 & 0.18 & 1.00 & - & - \\
\hline Parents' perception of child QoL & -0.20 & -0.18 & -0.26 & -0.11 & 1.00 & - \\
\hline Parent health state & -0.30 & -0.16 & -0.07 & -0.14 & 0.12 & 1.00 \\
\hline
\end{tabular}

Data presented are Pearson correlation coefficients

QoL quality of life, OM-6 Otitis Media-6 Questionnaire 
Table 5 Productivity loss due to the most recent acute otitis media (AOM) episode (hours)

\begin{tabular}{|c|c|c|c|}
\hline Productivity loss (h) & All patients $(n=110)$ & Recurrent $(n=4)$ & Non-recurrent $(n=106)$ \\
\hline \multicolumn{4}{|l|}{ Average missed work ${ }^{\mathrm{a}}$} \\
\hline$N$ & 42 & 2 & 40 \\
\hline Mean (SD) & $20.9(16.9)$ & $60.0(17.0)$ & $18.9(14.5)$ \\
\hline Median & 16.0 & 60.0 & 16.0 \\
\hline Min-max & $1.0-80.0$ & $48.0-72.0$ & $1.0-80.0$ \\
\hline \multicolumn{4}{|c|}{ Uncompensated work missed by mother ${ }^{\mathrm{b}}$} \\
\hline$N$ & 36 & 2 & 34 \\
\hline Mean (SD) & $19.7(20.9)$ & $72.0(33.9)$ & $16.6(15.9)$ \\
\hline Median & 16.0 & 72.0 & 16.0 \\
\hline Min-max & $0.0-96.0$ & $48.0-96.0$ & $0.0-80.0$ \\
\hline \multicolumn{4}{|c|}{ Uncompensated work missed by father ${ }^{\mathrm{b}}$} \\
\hline$N$ & 10 & 2 & 8 \\
\hline Mean (SD) & $23.4(15.0)$ & $48.0(0.0)$ & $17.3(8.5)$ \\
\hline Median & 24.0 & 48.0 & 20.0 \\
\hline Min-max & $2.0-48.0$ & $48.0-48.0$ & $2.0-24.0$ \\
\hline \multicolumn{4}{|c|}{ Compensated work missed } \\
\hline$N$ & 4 & 0 & 4 \\
\hline Mean (SD) & $18.0(15.2)$ & & $18.0(15.2)$ \\
\hline Median & 12.0 & & 12.0 \\
\hline Min-max & $8.0-40.0$ & & $8.0-40.0$ \\
\hline \multicolumn{4}{|c|}{ Extra hours needed to be as productive at work } \\
\hline$N$ & 44 & 3 & 41 \\
\hline Mean (SD) & $3.6(7.1)$ & $18.0(26.0)$ & $2.5(1.7)$ \\
\hline Median & 2.0 & 4.0 & 2.0 \\
\hline Min-max & $1.0-48.0$ & $2.0-48.0$ & $1.0-10.0$ \\
\hline \multicolumn{4}{|l|}{ Leisure time missed ${ }^{\mathrm{a}}$} \\
\hline$N$ & 62 & 2 & 60 \\
\hline Mean (SD) & $37.4(22.2)$ & $54.0(8.5)$ & $36.8(22.3)$ \\
\hline Median & 48.0 & 54.0 & 48.0 \\
\hline Min-max & $2.0-96.0$ & $48.0-60.0$ & $2.0-96.0$ \\
\hline
\end{tabular}

${ }^{a}$ If more than one parent/caregiver was missing hours, then the average hours missed among all caregivers was calculated for each child

$\mathrm{b}$ The total number of work hours missed minus the number of hours compensated differences in regional and urban/rural location (Table 1). Parents with paid employment took an average of $21 \mathrm{~h}$ from work to care for their child, with an associated financial loss, and also parental reduced productivity at work. These hours lost are comparable to those reported in European countries where indirect costs are reported to account for $61-83 \%$ of the total costs related to an AOM episode [14]. Considering the economic consequence of days away from work and reduced productivity at work, the total, true economic burden would be substantially higher, affecting not only patients and their family but also causing an enormous burden at a societal level.

There were a few methodological limitations that might impact upon the generalizability of the results of the current study. First, the surveyed patients were mostly recruited through ENT specialists, while in actual practice many cases present and are managed by other specialists or indeed within primary care. Previous studies evaluating incidence and QoL in OM have recruited subjects from a variety of differing populations, including ENT clinics [21], primary care [6], and by random calling [12]. In these previous studies, and in our study, it remains difficult to determine the effect of selection bias on the outcomes reported. While we have attempted to reduce selection bias by recruiting at different hospital centers, each of which serves different patient populations, it remains difficult to determine how representative of the local "real world" population our overall cohort is. A number of eligible subjects were recruited or considered eligible for inclusion, but the parents could not participate in the survey for a 
Table 6 Financial loss due to the most recent acute otitis media (AOM) episode (Malaysian ringgit [RM] and US\$)

\begin{tabular}{|c|c|c|c|c|c|c|}
\hline \multirow[t]{2}{*}{ Financial loss (wages) } & \multicolumn{2}{|c|}{ All patients $(n=110)$} & \multicolumn{2}{|l|}{ Recurrent $(n=4)$} & \multicolumn{2}{|c|}{ Non-recurrent $(n=106)$} \\
\hline & RM & US\$ & $\mathrm{RM}$ & US\$ & RM & US\$ \\
\hline \multicolumn{7}{|c|}{ Cost, average missed work ${ }^{\mathrm{a}}$} \\
\hline$N$ & 42 & & 2 & & 40 & \\
\hline Mean (SD) & $321.8(386.4)$ & $96.6(116.0)$ & $1,265.6(358.0)$ & $380.1(107.5)$ & $274.7(325.2)$ & $22.4(97.7)$ \\
\hline Median & 168.8 & 50.7 & $1,265.6$ & 380.1 & 168.8 & 50.7 \\
\hline Min-max & $16.4-1,875.2$ & $4.92-568.2$ & $1,012.5-1,518.8$ & $304.1-456.1$ & $16.4-1875.3$ & $4.92-568.2$ \\
\hline \multicolumn{7}{|c|}{ Cost, uncompensated work missed by mother ${ }^{\mathrm{b}}$} \\
\hline$N$ & 36 & & 2 & & 34 & \\
\hline Mean (SD) & $319.9(467.2)$ & $96.1(140.3)$ & $1,518.8(716.0)$ & $456.1(215.0)$ & $249.3(351.7)$ & $74.9(105.6)$ \\
\hline Median & 131.3 & 39.4 & $1,518.8$ & 456.1 & 131.3 & 39.4 \\
\hline Min-max & $0.0-2,025.0$ & $0-608.1$ & $1,012.5-2,025.0$ & $304.1-608.1$ & $0.0-1875.3$ & $0-563.2$ \\
\hline \multicolumn{7}{|c|}{ Cost, uncompensated work missed by father ${ }^{\mathrm{b}}$} \\
\hline$N$ & 10 & & 2 & & 8 & \\
\hline Mean (SD) & $379.8(368.2)$ & $114.1(110.6)$ & $1,012.5(0.0)$ & $304.1(0.0)$ & $221.6(176.9)$ & $66.5(53.1)$ \\
\hline Median & 225.0 & 67.6 & $1,012.5$ & 304.1 & 168.8 & 50.7 \\
\hline Min-max & $32.8-1,012.5$ & $9.85-304.1$ & $1,012.5-1,012.5$ & $304.1-304.1$ & $32.8-562.6$ & $9.85-168.9$ \\
\hline \multicolumn{7}{|c|}{ Cost, compensated work missed } \\
\hline$N$ & 4 & & 0 & & 4 & \\
\hline Mean (SD) & $220.3(167.3)$ & $66.2(50.2)$ & - & - & $220.3(167.3)$ & $66.2(50.2)$ \\
\hline Median & 150.0 & 45.0 & - & - & 150.0 & 45.0 \\
\hline Min-max & $112.5-468.8$ & $33.8-140.8$ & - & - & $112.5-468.8$ & $33.8-140.8$ \\
\hline \multicolumn{7}{|c|}{ Cost, extra hours needed to be as productive at work } \\
\hline$N$ & 44 & & 3 & & 41 & \\
\hline Mean (SD) & $53.3(150.5)$ & $16.0(45.2)$ & $367.6(559.9)$ & $110.4(168.1)$ & $30.3(26.7)$ & $9.1(8.0)$ \\
\hline Median & 23.4 & 7.0 & 84.4 & 25.2 & 23.4 & 7.0 \\
\hline Min-max & $3.0-1,012.5$ & $0.9-304.1$ & $5.9-1,012.5$ & $1.8-304.1$ & $3.0-131.3$ & $0.9-39.4$ \\
\hline
\end{tabular}

Only available/non-missing responses were included in the analyses. Actual wage lost could be underestimated in some cases. Wages lost are based on hourly wage computed from reported individual monthly income range. 1 US $\$=3.33$ RM

${ }^{a}$ If more than one parent/caregiver was missing hours, then the average hours missed among all caregivers was calculated for each child

b Wage loss calculated based on the total number of work hours missed minus the number of hours compensated

variety of reasons, and their absence could also have contributed to selection bias, although this is difficult to quantify.

Additional areas of potential bias exist. In the present study, differences in child and parental demographics were reported. These include intensity of treatment required, household income (as mentioned above), level of parental education (in which over $50 \%$ of parents surveyed had tertiary education), and health insurance status, with $50 \%$ of children having no insurance cover. Our study was not specifically designed to examine differences in QoL outcomes on the basis of these demographic differences, and indeed as the numbers in any specific demographic group would be small, any such analysis would be viewed with caution. However, it remains that any unquantified differences in QoL outcomes associated with demographic variations may impact upon their relevance to the wider population. An additional limitation is that, while informative, we also realise that the indirect costs and time lost we report are based on a relatively small sample size and may not necessarily be representative of the larger population. A more ideal study would include a full range of social and clinical demographics. This would demand a larger study population with a greater variety and range of AOM including recurrent AOM, to better determine the QoL and economic impact on a wider and more representative scale.

Nevertheless, we believe that the data we report provides a useful baseline for the Malaysian population, in particular as this is the first study to investigate the QoL and indirect-cost burden of AOM episodes in Malaysia. The strengths of this study involved a rigorous research methodology with instruments developed for use in AOM and which, although not fully validated, was shown to demonstrate a high level of internal consistency reliability for the various components in European children with 
AOM [20]. We adapted this set of questionnaires for the local Malaysian population, using established principles with immediate interviewer electronic data entry to reduce error. While internet-based data collection allows more rapid collection, and can involve larger study populations, we believed that an internet questionnaire may not be appropriate for Malaysia and indeed may exclude those families without easy internet access, especially in a rural area. As such, face-to-face interviews were conducted to accommodate cultural attitudes, and be more inclusive.

\section{Conclusions}

AOM presents a significant burden on affected young children, their parents, and society. We investigated the impact of an AOM episode on the child's and parent's QoL, caregiver concerns, and indirect costs associated with work and productivity losses. We found a negative impact of AOM on parental and child QoL, thus providing useful country-specific data on AOM burden in Malaysia. The indirect costs reported highlight an additional burden which may apply to other populations.

Acknowledgements The authors wish to thank all participating physicians, patients, and interview respondents for study participation. The authors would like to thank all staff at the clinical research centers involved in this study [the University Malaya, Kuala Lumpur; the Universiti Kebangsaan Malaysia (UKM) Medical Centre, Kuala Lumpur; and the Hospital Sultanah Bahiyah, Alor Star, Kedah]. The authors thank Ms Hafiza Johari, Dr Rahimah Aini, and Dr Kong Min Han. The authors thank Iain O'Neill for scientific writing support (funded by GlaxoSmithKline Biologicals SA) and Fabien Debailleul (Business and Decision Life Sciences on behalf of GSK Vaccines) for publication coordination.

\section{Compliance with Ethical standards}

Funding This study and all costs associated with the development and publication of this manuscript were funded by GlaxoSmithKline Biologicals SA.

Competing interests Bruce Crawford, Keiko Wada, Cheryl Coon, and Michael DeRosa are or were employees of the Adelphi Values who were paid consultants to GSK in connection with the development of this study and manuscript. Adelphi Values received consulting fees from the GSK group of companies for the design and implementation of the study, conduct of the data analysis and writing of the summary report. Genevieve Meier and Emmanuelle Delgleize are or were employees of the GSK group of companies and report ownership of restricted shares from the GSK group of companies. Siti Sabzah Mohd Hashim, Narayanan Prepageran, and Goh Bee See report no conflicts of interest.

Ethical approval The study protocol was reviewed and approved by the ethics board of each participating center (the University of Malaya and the National University of Malaysia) and Sultanah Bahiyah Hospital. The study was conducted in accordance with the Declaration of Helsinki and guidelines on good clinical practice.
Open Access This article is distributed under the terms of the Creative Commons Attribution-NonCommercial 4.0 International License (http://creativecommons.org/licenses/by-nc/4.0/), which permits any noncommercial use, distribution, and reproduction in any medium, provided you give appropriate credit to the original author(s) and the source, provide a link to the Creative Commons license, and indicate if changes were made.

\section{References}

1. Rovers MM. The burden of otitis media. Vaccine. 2008;26(Suppl 7):G2-4.

2. Monasta L, Ronfani L, Marchetti F, Montico M, Vecchi Brumatti L, Bavcar A, et al. Burden of disease caused by otitis media: systematic review and global estimates. PLoS One. 2012;7:e36226.

3. Hansen MP, Jarbol DE, Gahrn-Hansen B, Depont Christensen R, Munck A, Ellegaard Trankjær Ryborg C, et al. Treatment of acute otitis media in general practice: quality variations across countries. Fam Pract. 2012;29(1):63-8.

4. Vergison A, Dagan R, Arguedas A, Bonhoeffer J, Cohen R, Dhooge I, et al. Otitis media and its consequences: beyond the earache. Lancet Infect Dis. 2010;10(3):195-203.

5. Brouwer CN, Rovers MM, Maillé AR, Veenhoven RH, Grobbee DE, Sanders EA, et al. The impact of recurrent acute otitis media on the quality of life of children and their caregivers. Clin Otolaryngol. 2005;30(3):258-65.

6. Liese JG, Silfverdal SA, Giaquinto C, Carmona A, Larcombe JH, Garcia-Sicilia J, et al. Incidence and clinical presentation of acute otitis media in children aged $<6$ years in European medical practices. Epidemiol Infect. 2014;142(8):1778-88.

7. Mahadevan M, Navarro-Locsin G, Tan HK, Yamanaka N, Sonsuwan N, Wang PC, et al. A review of the burden of disease due to otitis media in the Asia-Pacific. Int J Pediatr Otorhinolaryngol. 2012;76(5):623-35.

8. Boruk M, Lee P, Faynzilbert Y, Rosenfeld RM. Caregiver wellbeing and child quality of life. Otolaryngol Head Neck Surg. 2007;136(2):159-68.

9. Rosenfeld RM, Goldsmith AJ, Tetlus L, Balzano A. Quality of life for children with otitis media. Arch Otolaryngol Head Neck Surg. 1997;123(10):1049-54.

10. Berdeaux G, Hervie C, Smajda C, Marquis P. Parental quality of life and recurrent ENT infections in their children: development of a questionnaire. Rhinitis Survey Group. Qual Life Res. 1998;7(6):501-12.

11. Brouwer CN, Maillé AR, Rovers MM, Veenhoven RH, Grobbee DE, Sanders EA, et al. Effect of pneumococcal vaccination on quality of life in children with recurrent acute otitis media: a randomized, controlled trial. Pediatrics. 2005;115(2):273-9.

12. Dube E, De Wals P, Ouakki M. Quality of life of children and their caregivers during an AOM episode: development and use of a telephone questionnaire. Health Qual Life Outc. 2010;8:75.

13. Aljunid S, Maimaiti N, Ahmed Z, Nur AM, Isa ZM, Azmi S, et al. Economic impact of pneumococcal Protein-D conjugate vaccine (PHiD-CV) on the Malaysian national immunization programme. Value Health (Regional). 2014;3C:146-55.

14. Wolleswinkel-van den Bosch JH, Stolk EA, Francois M, Gasparini R, Brosa M. The health care burden and societal impact of acute otitis media in seven European countries: results of an internet survey. Vaccine. 2010;28(Suppl 6):G39-52.

15. Saim A, Saim L, Saim S, Ruszymah BH, Sani A. Prevalence of otitis media with effusion amongst pre-school children in Malaysia. Int J Pediatr Otorhinolaryngol. 1997;41(1):21-8. 
16. Tikaram A, Chew Y, Zulkiflee A, Cong A, Prepageran N. Prevalence and risk factors associated with otitis media with effusion in children visiting tertiary care centre in Malaysia. Int Med J Malaysia. 2012;11(1):37-40.

17. Zulkiflee S, Asma A, Philip R, Siti Sabzah M, Sobani D, Nik Khairulddin NY, et al. A systematic review of management of otitis media with effusion in children. $\mathrm{Br} \mathrm{J}$ Med Med Res. 2014;4(11):2119-28.

18. Beaton DE, Bombardier C, Guillemin F, Ferraz MB. Guidelines for the process of cross-cultural adaptation of self-report measures. Spine (Phila Pa 1976). 2000;25(24):3186-91.

19. Wild D, Grove A, Martin M, Eremenco S, McElroy S, VerjeeLorenz A, et al. ISPOR task force for translation and cultural adaptation. Principles of good practice for the translation and cultural adaptation process for patient-reported outcomes (PRO) measures: report of the ISPOR task force for translation and cultural adaptation. Value Health. 2005;8(2):94-104.

20. Holl K, Rosenlund M, Giaquinto C, Silfverdal SA, Carmona A, Larcombe J, et al. The impact of childhood acute otitis media on parental quality of life in a prospective observational cohort study. Clin Drug Investig. 2015;35(10):613-24.

21. Heidemann C, Godballe C, Kjeldsen A, Johansen E, Faber C, Lauridsen H. The Otitis Media-6 questionnaire: psychometric properties with emphasis on factor structure and interpretability. Health Qual Life Outc. 2013;11:201.

22. The EuroQol Group. EuroQol-a new facility for the measurement of health-related quality of life. Health Policy. 1990;16(3):199-208.

23. Shafie AA, Hassali MA, Liau SY. A cross-sectional validation study of EQ-5D among the Malaysian adult population. Qual Life Res. 2011;20(4):593-600.

24. Yusof FA, Goh A, Azmi S. Estimating an EQ-5D value set for Malaysia using time trade-off and visual analogue scale methods. Value Health. 2012;15(1 Suppl):S85-90.

25. von Elm E, Altman DG, Egger M, Pocock SJ, Gotzsche PC, et al. STROBE initiative. The Strengthening the Reporting of Observational Studies in Epidemiology (STROBE) statement: guidelines for reporting observational studies. Epidemiology. 2007;18(6):800-4.

26. Speets A, Wolleswinkel J, Cardoso C. Societal costs and burden of otitis media in Portugal. J Multidiscip Healthc. 2011;4:53-62.

27. Barber C, Ille S, Vergison A, Coates H. Acute otitis media in young children-what do parents say? Int J Pediatr Otorhinolaryngol. 2014;78(2):300-6. 